\title{
Transformation of multi-component ginkgolide into ginkgolide B by Coprinus comatus
}

\author{
HongXue Ding ${ }^{1 \dagger}$, ZhiCai Zhang ${ }^{1 *}$, ShengNan Cao ${ }^{1 \dagger}$, Yin $\mathrm{Xu}^{1 \dagger}$ and JianGuo $\mathrm{Yu}^{2 \dagger}$
}

\begin{abstract}
Background: As the strongest antagonist of the platelet activating factor, ginkgolide B (GB) possesses anti-ischemic, anti-oxidant and anti-convulsant properties, and it is used for the treatment of thrombosis in clinical practice. Till now, GB is usually obtained from extraction of Ginkgo biloba leaves through column chromatography with an extremely low yield and high cost, which can not meet clinical requirement. Therefore, it is urgent to find a new method to prepare GB.

Results: In the current study, we studied the ability and mechanism to transform multi-component ginkgolide into GB by Coprinus comatus in order to enhance the GB yield. Except for ginkgolide A (GA) and GB, all the other ginkgolides in the extract were transformed by the strain. In the case of culture medium containing $20 \mathrm{~g} / \mathrm{L}$ glucose, the transformation product was identified as 12\% GA and $88 \%$ GB by high performance liquid chromatography-Mass spectrometry (HPLC-MS), two stage mass spectrometry (MS/MS) and nuclear magnetic resonance (NMR). Partial GA was also transformed into GB according to the yield (76\%) and the content of GA in the raw ginkgolide (28.5\%). Glucose was the key factor to transform ginkgolides. When glucose concentration in medium was higher than $40 \mathrm{~g} / \mathrm{L}$, all ginkgolides were transformed into the GB. Proteomic analysis showed that $C$. comatus transformed ginkgolide into GB by producing 5 aldo/keto reductases and catalases, and enhancing the metabolism of glucose, including Embden-Meyerhof pathway (EMP), hexose monophophate pathway (HMP) and tricarboxylic acid (TCA).

Conclusions: C. comatus could transform ginkgolides into GB when the medium contained $40 \mathrm{~g} / \mathrm{L}$ glucose. When the strain transformed ginkgolides, the glucose metabolism was enhanced and the strain synthesized more aldo/ keto reductases and catalases. Our current study laid the groundwork for industrial production of GB.
\end{abstract}

Keywords: Ginkgolide B, Bio-transformation, Coprinus comatus, Proteomic analysis

\section{Background}

The extracts of Ginkgo biloba leaves (EGB) possess antiischemic [1-3], anti-oxidant [4-6] and anti-convulsant properties [7]. A great deal of evidence supports that the bioactive components of EGB, including the terpene trilactones (TTLs) and flavonoids, have significant therapeutic effects on age-related physical and mental deterioration as well as cerebral vascular insufficiency, such as Alzheimer's and cardiovascular diseases [8-10]. TTLs consist of ginkgolide A (GA), ginkgolide B (GB), ginkgolide C $(\mathrm{GC})$, ginkgolide J (GJ) (Figure 1) and bilobalide (BB)

\footnotetext{
* Correspondence: zhangtamei@163.com

${ }^{\dagger}$ Equal contributors

'School of Food Science and Biotechnology, Jiangsu University, Zhenjiang, Jiangsu 212013, P. R. China

Full list of author information is available at the end of the article
}

[11]. As the main bioactive constituents of EGB, TTLs impart broad spectrum of pharmacological activities to plants.

Among TTLs, GB has many pharmacological functions, including anti-inflammatory, anti-tumor and ischemiareperfusion protection effects, and it has long been used to treat central nervous system's diseases, such as degenerative dementia and neurosensory disorders [12]. GB is the strongest antagonist of the platelet activating factor and used for the treatment of thrombosis in clinical practice $[13,14]$. However, the chemosynthesis of GB is very difficult due to its unique structure, and the yield of $G B$ from EGB by chromatographic separation remains very low. Different methods have been reported to improve GB preparation [15-19], but they are all difficult to apply into industrial production.

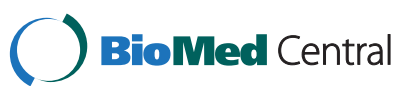

(c) 2015 Ding et al.; licensee BioMed Central. This is an Open Access article distributed under the terms of the Creative Commons Attribution License (http://creativecommons.org/licenses/by/4.0), which permits unrestricted use, distribution, and reproduction in any medium, provided the original work is properly credited. The Creative Commons Public Domain Dedication waiver (http://creativecommons.org/publicdomain/zero/1.0/) applies to the data made available in this article, unless otherwise stated. 


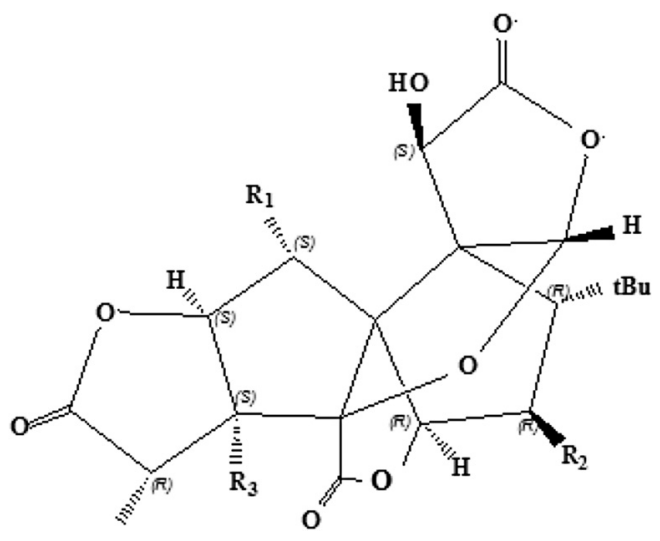

Figure 1 The structure of ginkgolide (G). $G A: R_{1}=R_{2}=H, R_{3}=O H$; GB: $R_{1}=R_{3}=O H, R_{2}=H ; G C: R_{1}=R_{2}=R_{3}=O H ; G J: R_{1}=H, R_{2}=R_{3}=$ $\mathrm{OH} ; \mathrm{GM}: \mathrm{R}_{1}=\mathrm{R}_{2}=\mathrm{OH}, \mathrm{R}_{3}=\mathrm{H}$

Bio-transformation is an efficient approach to modify structures of complex natural products [20,21]. Biotransformation reaction has many advantages, such as high regio- and stereo-selectivity; and mild reaction conditions compared with chemical synthetic methods $[21,22]$. Till now, many novel chemicals have been obtained from the monomers of natural compounds by this transformation approach, including flavonoids [23], terpenoides [24], saponins [25] and alkanes [26]. Few studies reported that one type of natural compound is synchronously transformed by one specific strain. In our previous studies, we proved that the edible and medicinal fungi can enhance biological functions of herbs through bio-transformation [27-30]. However, very limited information is available on how these edible and medicinal fungi transform the components of herbs. In order to explore its underlying mechanism, we compared the different edible and medicinal fungi, including Lentinus edodes, Agaricus bisporus, Coprinus comatus, Ganoderma lucidum, Hericium erinaceus, Pleurotus ostreatus, Pleurotus eryngii, Boletus edulis and Cordyceps sinensis, and components of herbs, including flavonoids, terpenoids, alkaloids, anthraquinones and so on. We found that many edible and medicinal could transform natural components of herbs; especially C. comatus could transform ginkgolide.

In the present study, we separated the transformation products of total ginkgolide by Coprinus comatus UJS03 through extraction and recrystallization. Moreover, we analyzed the structure of its individual components by comparing the retention time of high performance liquid chromatography (HPLC), nuclear magnetic resonance (NMR), infra-red spectrum (IR spectrum) and mass spectrum (MS) with the corresponding spectra of their standard substances. Taken together, this is the first study reporting that one type of compounds was synchronously converted into a simple compound by one specific strain through bio-transformation.

\section{Methods}

Microorganisms, media and culture conditions

A culture of C. comatus UJS03 was kindly provided by Anhui Bioscience \& Technology Co., Ltd. The stock culture was maintained on potato dextrose agar (PDA) slants at $25^{\circ} \mathrm{C}$ for 9 days and then stored at $4^{\circ} \mathrm{C}$. Total ginkgolide, composed of GA $28.50 \%$, GB $21.26 \%$, GC $24.15 \%$, GM $8.69 \%$, GJ $11.12 \%$ and BB $6.28 \%$, was purchased from Xuzhou Kangruilai Bio-production Co., Ltd. (Xuzhou, China). The standards of GA and GB were obtained from Chinese Food \& Drug Inspection Institute.

The medium applied in the transformation experiments was prepared using distilled water and composed of following components: glucose $20 \mathrm{~g} / \mathrm{L}$, corn powder $15 \mathrm{~g} / \mathrm{L}$, wheat bran $5 \mathrm{~g} / \mathrm{L}, \mathrm{KH}_{2} \mathrm{PO}_{4} 2 \mathrm{~g} / \mathrm{L}, \mathrm{MgSO}_{4} \cdot 7 \mathrm{H}_{2} \mathrm{O}$ $3 \mathrm{~g} / \mathrm{L}$, yeast extract $2 \mathrm{~g} / \mathrm{L}$ and corn steep powder $5 \mathrm{~g} / \mathrm{L}$. A $250-\mathrm{mL}$ flask containing $60 \mathrm{~mL}$ medium was inoculated by punching out $5 \mathrm{~mm}$ of the agar slant culture with a self-designed cutter. The seed culture was grown in a rotary shaker at $150 \mathrm{rpm}$ and $25^{\circ} \mathrm{C}$ for 7 days. Subsequently, $10 \mathrm{~mL}$ seed culture was inoculated into other 250-mL flasks containing similar medium and $0.5 \%$ total ginkgolide, which were incubated under the same conditions for 7 days. The broth was used to extract ginkgolide. The biomass was used in proteomics analysis, and the biomass without ginkgolide supplementation served as the control in proteomic analysis.

\section{Isolation and purification of transformed ginkgolide products}

The broth and mycelium were separated through filtration after $168 \mathrm{~h}$ of incubation. The mycelia was dried at $80^{\circ} \mathrm{C}$ until a constant weight and then extracted at $80^{\circ} \mathrm{C}$ using 10 volumes of ethanol $(\mathrm{v} / \mathrm{w})$ for three times. The obtained extracts as well as the filtrate were combined and dried in rotary-evaporator under vacuum. The dried extract was dissolved using 10 volumes of ethyl acetate $(\mathrm{v} / \mathrm{w})$ at the room temperature. The resulting solution was filtrated, and the filtrate was washed by $3 \% \mathrm{NaHCO}_{3}$ for three times and then concentrated to dry. The residual was dissolved with 10 volumes of ethanol. The solution was precipitated for $6 \mathrm{~h}$ by adding three volumes of distilled water $(\mathrm{v} / \mathrm{v})$. The precipitate was dissolved in small amount of ethanol and recrystallized at $-20^{\circ} \mathrm{C}$ for $6 \mathrm{~h}$. The crystal was obtained through filtration, washed with distilled water and then dried under the infrared ray. 


\section{Analysis of GA and GB contents Analysis of HPLC}

HPLC analysis was performed on a Water Xbridge BEH C18 column $(2.5 \mu \mathrm{m}, 3.0 \times 100 \mathrm{~mm})$ using high pressure binary pump, Waters 996 diode array detector and Agilent 1200 Series auto-sampler. The elution was obtained with a gradient of methanol $(70 \%)$ and water $(30 \%)$ at a flow rate of $0.2 \mathrm{~mL} / \mathrm{min}$. The HPLC system was coupled with a Agilent three-stage quadrupole mass spectrometry 6400 ion trap mass spectrometer (USA) operated in the mode of full-scan negative ion electrospray ionization (ESI) $(\mathrm{m} / \mathrm{z}$ 500-800). MS parameters were optimized to maximum sensitivity as follows: ESI, negative polarity ionization; spray voltages: $4.0 \mathrm{kV}$; heating capillary temperature: $275^{\circ} \mathrm{C}$; sheath gas $\left(\mathrm{N}_{2}\right)$ flow: $30 \mathrm{Arb}$; Aux/sweep gas $\left(\mathrm{N}_{2}\right)$; flow rate: 50 Arb.

\section{Analysis of NMR and mass spectra}

The ${ }^{1} \mathrm{H}$ and ${ }^{13} \mathrm{C}$ NMR spectra were determined using the Bruker Avance III 500 spectrometer instrument. Highresolution mass spectra were recorded on an LCQ-DECA ion trap spectrometer (ThermoFisher, USA) using ESI in negative polarity ionization.

\section{Comparative proteomic analysis of $C$. comatus in response to ginkgolide challenge \\ Frozen protein extraction}

Frozen C. comatus mycelia (5 g) cultured in abovementioned medium with or without ginkgolide supplementation were finely powdered in liquid nitrogen and homogenized in ice-cold homogenizing buffer, containing $1.05 \mathrm{~mol} \mathrm{~L}^{-1}$ sucrose, $60 \mathrm{mmol} \mathrm{L}^{-1}$ Tris, $10 \mathrm{mmol} \mathrm{L}^{-1}$ ethylene glycol bis (2-aminoethyl) tetraacetic acid (EGTA), $1 \mathrm{mmol} \mathrm{\textrm {L } ^ { - 1 }}$ phenylmethanesulfonyl fluoride (PMSF), $1 \mathrm{mmol} \mathrm{L}^{-1}$ dithiothreitol (DTT) and 1\% (v/v) Triton $\mathrm{X}-100, \mathrm{pH}$ 8.35. The homogenate was centrifuged at $5,000 \times \mathrm{g}$ for $15 \mathrm{~min}$ at room temperature, and the supernatant was collected and centrifuged again. The supernatant was the protein extracts and stored at $-80^{\circ} \mathrm{C}$ for isoelectric focusing (IEF). The concentrations of the protein extracts were determined by the Bradford method [31].

\section{Two-dimensional electrophoresis (DE)}

The sample aliquots containing $1,500 \mu \mathrm{g}$ proteins were mixed with fresh rehydration buffer, consisting of $9 \mathrm{~mol} / \mathrm{L}$ urea, 4\% 3-[(3-Cholanidopropyl)dimethylammonio]-1-propanesulfonate, $1 \%$ DTT, 1\% immobilized pH gradient (IPG buffer) (GE Healthcare) and trace amount of bromophenol blue, to a total volume of $450 \mu \mathrm{L}$. Samples were placed into the strip holder (GE Healthcare, $24 \mathrm{~cm}, \mathrm{pH}=3-10, \mathrm{NL}$ ) after the drystrips were obtained from $-20^{\circ} \mathrm{C}$ freezer and placed at room temperature for $10 \mathrm{~min}$. IEF was performed on an IPGhor IEF System (GE Healthcare). Parameters for
IEF were set as follows: temperature: $20^{\circ} \mathrm{C} ; 50 \mu \mathrm{A}$ per strip; rehydration at $50 \mathrm{~V}$ for $12 \mathrm{~h}$ (step), $500 \mathrm{~V}$ for $1 \mathrm{~h}$ (step), $1,000 \mathrm{~V}$ for $1 \mathrm{~h}$ (step), 10,000 V for $1 \mathrm{~h}$ (gradient), 10,000 V for $11 \mathrm{~h}$ (step).

The strips were gotten from the strip holder, and the redundant oil and protein solution were absorbed by filter paper. The strips were incubated in equilibration buffer 1, containing $6 \mathrm{~mol} / \mathrm{L}$ urea, 30\% glycerol, $2 \%$ sodium dodecyl sulphate (SDS), $50 \mathrm{mM}$ Tris- $\mathrm{HCl}$ (pH 8.8), 1\% DTT and trace amount of bromophenol blue, for $15 \mathrm{~min}$ and then in equilibration buffer 2, containing $6 \mathrm{~mol} / \mathrm{L}$ urea, 30\% glycerol, 2\% SDS, $50 \mathrm{mM}$ Tris- $\mathrm{HCl}(\mathrm{pH}$ 8.8), 2.5\% Iodoacetamide and trace amount of bromophenol blue, for $15 \mathrm{~min}$. The strip was then removed and rinsed with SDS electrophoresis buffer $(25 \mathrm{mmol} / \mathrm{L}$ Tris, $192 \mathrm{mmol} / \mathrm{L}$ glycine, $0.1 \% \mathrm{SDS})$ for $10 \mathrm{sec}$. After melted, the sealing solution $(25 \mathrm{mmol} / \mathrm{L}$ Tris, $192 \mathrm{mmol} / \mathrm{L}$ glycine, $0.1 \%$ SDS, $0.5 \%$ agarose) was added to the surface of the SDS-PAGE gel (12\% SDS gel solution: $12 \%$ acrylamide, $0.32 \% \mathrm{~N}$ N'-methylenebisacrylamide, $0.375 \mathrm{~mol} / \mathrm{L} \mathrm{pH}$ 8.8, Tris-HCL, 0.1\% SDS, 0.05\% ammonium persulphate, $0.05 \% \mathrm{~N}, \mathrm{~N}, \mathrm{~N}, \mathrm{~N}^{\prime}$-Tetramethylethyl -enediamine (TEMED)), and the strip was laid across the top of the gel to make sure that the strip could be flushed with the gel. After the sealing solution was solidified, the gel was then moved to the electrophoresis apparatus for electrophoresis with parameters as follows. The equipment was Ettan-DALT-Six system; the temperature was at $15^{\circ} \mathrm{C}$; gel running time was $45 \mathrm{~min}$ at $100 \mathrm{~V}$ and then $6-8 \mathrm{~h}$ at $200 \mathrm{~V}$.

\section{Protein staining and analysis of 2-D gels}

After the electrophoresis, the gel was stained with Coomassie brilliant blue (CBB) according to Candiano's protocol [32]. All gel images were processed by three steps, spot detection, volumetric quantification and matching, using Pdquest 8.0 software. The differences in protein content between treatment and control groups were determined as the fold ratio. Spots of $\geq 2$ fold or $\leq 0.5$ fold thresholds with a $p$ value of less than 0.05 were excised from the gels, washed with double-distilled water and then transferred to sterilized Eppendorf tubes.

In-gel protein digestion and identification by matrixassisted laser desorption/ionization time-of-flight (MALDITOF/TOF)

The different protein spots were destained with $25 \mathrm{mmol} / \mathrm{L}$ $\mathrm{NH}_{4} \mathrm{HCO}_{3}$ and $50 \%$ acetonitrile (ACN) at room temperature for $30 \mathrm{~min}$, and then they were sequentially dehydrated in 50\% acetonitrile for $30 \mathrm{~min}$ and $100 \%$ acetonitrile for $30 \mathrm{~min}$. After removing $100 \% \mathrm{ACN}$, the proteins were digested with $0.02 \mu \mathrm{g} / \mu \mathrm{L}$ trypsin (Promega, USA) at $37^{\circ} \mathrm{C}$ overnight (about $16 \mathrm{~h}$ ). After hydrolysis, the supernatants were transferred into another tube. The residual gel was 
extracted again with extraction solution (5\% trifluoroacetic acid (TFA), $67 \% \mathrm{ACN}$ ) at $37^{\circ} \mathrm{C}$ for $30 \mathrm{~min}$ and then centrifuged for $5 \mathrm{~min}$. The obtained supernatant was combined, completely dried and re-suspended in $5 \mu \mathrm{L} 0.1 \%$ TFA. Subsequently, it was mixed with equal volume of matrix consisting of a saturated solution of $\alpha$-cyano-4-hydroxytrans-cinnamic acid in 50\% ACN, 0.1\% TFA. Then $1 \mu \mathrm{L}$ mixture was spotted on a stainless steel sample target plate. Peptide MS and MS/MS were performed on an ABI 5800 MALDI-TOF/TOF Plus mass spectrometer (Applied Biosystems, Foster City, USA). Data were acquired in a positive MS reflector using a CalMix5 standard to calibrate the instrument (ABI4800 Calibration Mixture). Both the MS and MS/MS data were integrated and processed by using the GPS Explorer V3.6 software (Applied Biosystems, USA) with default parameters. Based on combined MS and MS/MS spectra, proteins were successfully identified based on $95 \%$ or higher confidence interval of their scores in the MASCOT V2.3 search engine (Matrix Science Ltd., London, U.K.) according to following parameters: NCB Inr-Funji database; trypsin as the digestion enzyme; one missed cleavage site; fixed modifications of Carbamidomethyl (C); partial modifications of Acetyl (Protein N-term), Deamidated (NQ), Dioxidation (W), Oxidation (M); 100 ppm for precursor ion tolerance and 0.5 Da for fragment ion tolerance.

\section{Results and discussion}

The yield and analysis of the components of transformation products

Through bio-transformation of the total ginkgolide by $C$. comatus, the yield of GB was $76 \%$ and much higher compared with those obtained using other extraction methods because the theoretical maximum GB yield of conventional methods could not be higher than the GB content in the raw materials $(26.12 \%)$. The control culture of $C$. comatus without ginkgolide supplementation did not produce GB. The result showed that C. comatus could not synthesize GB from scratch. Therefore, it suggested that $C$. comatus could transform other ginkgolides into the GB. To verify our deduction, all components of the product were analyzed with HPLC-MS, MS-MS and NMR spectra, respectively.

\section{Analysis of HPLC-MS}

The LC-MS/MS method was first applied to analyze the components of bio-transformation product. Its total ion chromatograms (in Figure 2A) only exhibited two peaks of which retention times and molecular ion peaks at $\mathrm{m} / \mathrm{z}$ were consistent with GA (5.745 $\mathrm{min}, 407$, Figure 2B) and GB (6.463 min, 423, Figure $2 \mathrm{C}$ ), respectively, and the peaks of GC, GM, GJ and BB were not detected. Therefore, these two peaks were deduced as the GA and $\mathrm{GB}$, and other compounds were transformed or degraded by C. comatus. However, the production yield (76\%) and total content of GA $(28.50 \%)$ and GB $(21.26 \%)$ in raw materials exhibited that the GC, GM and GJ were transformed into GA or GB if the two components in the production were GA and GB. Based on the external standard method and area of peaks, the content of GA and GB was $12 \%$ and $88 \%$, respectively.

\section{Analysis of MS/MS}

In order to further identify these two peaks, MS/MS was used to compare the mass spectra of the product and standards of GA and GB. The results showed that in the negative mode, the two molecular ion peaks $[\mathrm{M}-\mathrm{H}]^{-}$of sample were at $\mathrm{m} / \mathrm{z} 407$ and 423 in a mass spectrometry (Figure $3 \mathrm{~A}$ and $\mathrm{B}$ ), and their fragment spectra at $\mathrm{m} / \mathrm{z}$ 351 and 333 (Figure 3A) and 367, 345 (Figure 3B) were similar to those of the standard GA and GB, respectively. These results further proved that transformation products were GA and GB. In the spectra of MS/MS, the disappearance of molecular ion peak at $\mathrm{m} / \mathrm{z} 325$ demonstrated that $\mathrm{BB}$ was degraded or transformed by C. comatus. No detection of other molecular ion peaks also exhibited that the product did not contain other impurities other than GA and GB.

\section{Analysis of the ${ }^{1} \mathrm{H},{ }^{13} \mathrm{C}$ NMR and the heteronuclear singular} quantum correlation (HSQC) spectra

Analysis of the ${ }^{1} \mathrm{H},{ }^{13} \mathrm{C}$ NMR and the HSQC spectra (Figure 3C and D) showed the ${ }^{1} \mathrm{H}_{-}{ }^{1} \mathrm{H}$ COSY and ${ }^{1} \mathrm{H}_{-}-{ }^{13} \mathrm{C}$ HSQC spectra of the product. The signal assignments for ${ }^{1} \mathrm{H}$ NMR and ${ }^{13} \mathrm{C}$ NMR spectrometry in Figure $3 \mathrm{C}$ and $\mathrm{D}$ were shown in Tables 1 and 2. Table 2 reveals that two components of the product contained the same number of carbons and possessed the similar structure. The disappearance of 7-OH group (in Table 1) exhibited that the product did not contain GC, GM and GJ, which were transformed by $C$. comatu. The ${ }^{1} \mathrm{H},{ }^{13} \mathrm{C}$ NMR, and the COSY, HSQC spectra of two components in the product were consistent with the spectra of the standard GA and GB (Figure 3C and D). The significant difference of main carbon's chemical shift between GA and GB was found between C-1, C-5 and C-9 of two components. The chemical shift of hydrogen atom of the corresponding carbon atoms exhibited significant differences (Table 1). These differences were caused by the hydroxyl group in $\mathrm{C}-1$ of GB. The content of GA and GB was $12 \%$ and $88 \%$, respectively, based on the integral quantification of 10-hydroxyl groups in the ${ }^{1} \mathrm{H}^{1}{ }^{1} \mathrm{H}$ COSY spectra. Moreover, our data showed that no other ${ }^{1} \mathrm{H}$ NMR and ${ }^{13} \mathrm{C}$ spectrometry belonged to $\mathrm{GA}$ and $\mathrm{GB}$ in the ${ }^{1} \mathrm{H}_{-}{ }^{1} \mathrm{H}$ COSY and ${ }^{1} \mathrm{H}_{-}{ }^{13} \mathrm{C}$ HSQC spectra, confirming that no other impurities existed in the production.

In summary, the product contained two components of $\mathrm{GA}$ and $\mathrm{GB}$, and their contents were $12 \%$ and $88 \%$, 
(A)

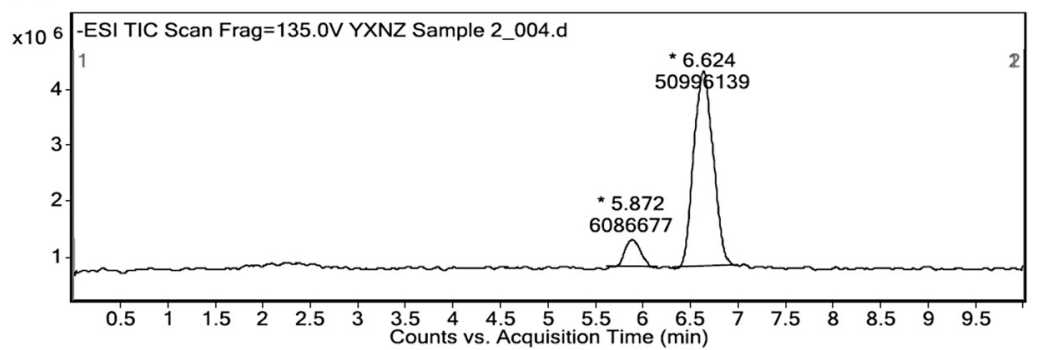

(B)

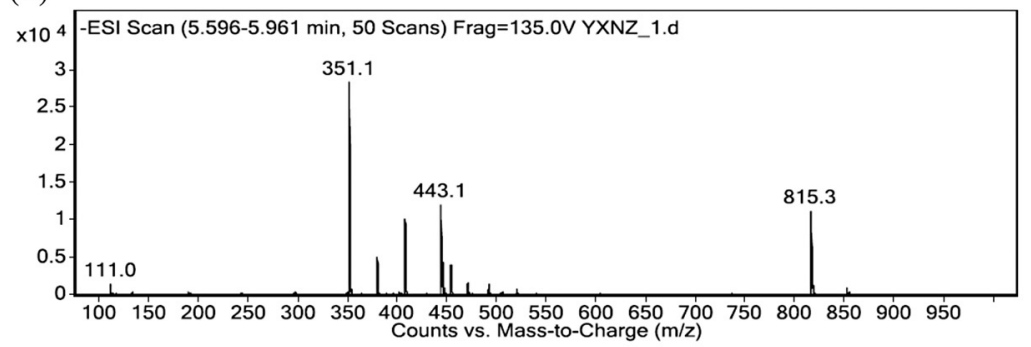

(C)

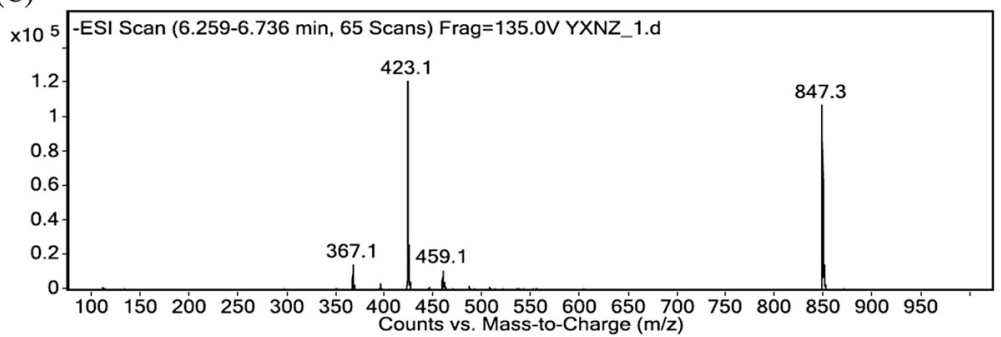

Figure 2 HPLC-MS chromatograms of the transformation product. (A) HPLC analysis of the product; (B) ESI-MS (-) MS spectrum of the retention time at $5.586 \mathrm{~min}$; (C) ESI-MS (-) MS spectrum of the retention time at $6.387 \mathrm{~min}$.

respectively. If GA in raw materials was not transformed to $\mathrm{GB}$, and other ginkgolides were all transformed into GB, the theoretical maximum content should be $72.5 \%$ because the GA content in raw materials was $28.5 \%$ and other ginkgolides content in raw materials was less than the true content of production (88\%). Based on the facts, it was believed that the partial GA was also transformed into GB or degraded.

\section{The mechanism of ginkgolide transformation into GB by C. comatus}

To disclose the mechanism that $C$. comatus transformed ginkgolides, the proteins difference of $C$. comatus biomass between transforming and un-transforming ginkgolide was analyzed. Comparative analysis of 2-DE gels between the medium with and without ginkgolide supplementation showed that the 24 proteins spots were differently expressed in response of the ginkgolide challenge (Figure 4A and B). Among these different proteins, six proteins were down-regulated and 18 proteins were up-regulated. The down-regulated proteins included chaperonin GroL (3711), succinate-CoA ligase (2710), NADP-binding protein (4701), hypothetical protein
HETIRDRAFT-413641 (4816), V-type ATPase (3909) and an unknown protein (4817). The up-regulated proteins included 6-phosphogluconate dehydrogenase (6108), glyceraldehyde 3-phosphate dehydrogenase (6302), glucose6-phosphate isomerase (8002), malate dehydrogenase (6303), 5 aldo/keto reductases $(6201,5119,5113,6103$, 1007), catalase (7820), UDP-glucose 4-epimerase (6402), cobalamin-independent methionine synthase (7204), acetamidase/formamidase (2803), cyclophilin (7203), 3 hypothetical protein $(5513,4513,5114)$ and an unknown protein (5008).

It is known that glucose-6-phosphate isomerase and glyceraldehyde 3-phosphate dehydrogenase are the rate limiting enzymes of Embden-Meyerhof pathway (EMP), 6-phosphogluconate dehydrogenase is the rate limiting enzyme of hexose monophophate pathway (HMP), and malate dehydrogenase is the rate limiting enzyme of tricarboxylic acid (TCA) cycle. Our data suggested that HMP, EMP and TCA involved into glucose metabolism were enhanced in the response of ginkgolide challenge. In the HMP, 1 mol glucose-6-phosphate is converted into the 6-phosphogluconate and ribulose-5-phsphate by two steps of dehydrogenation reaction, which produces 


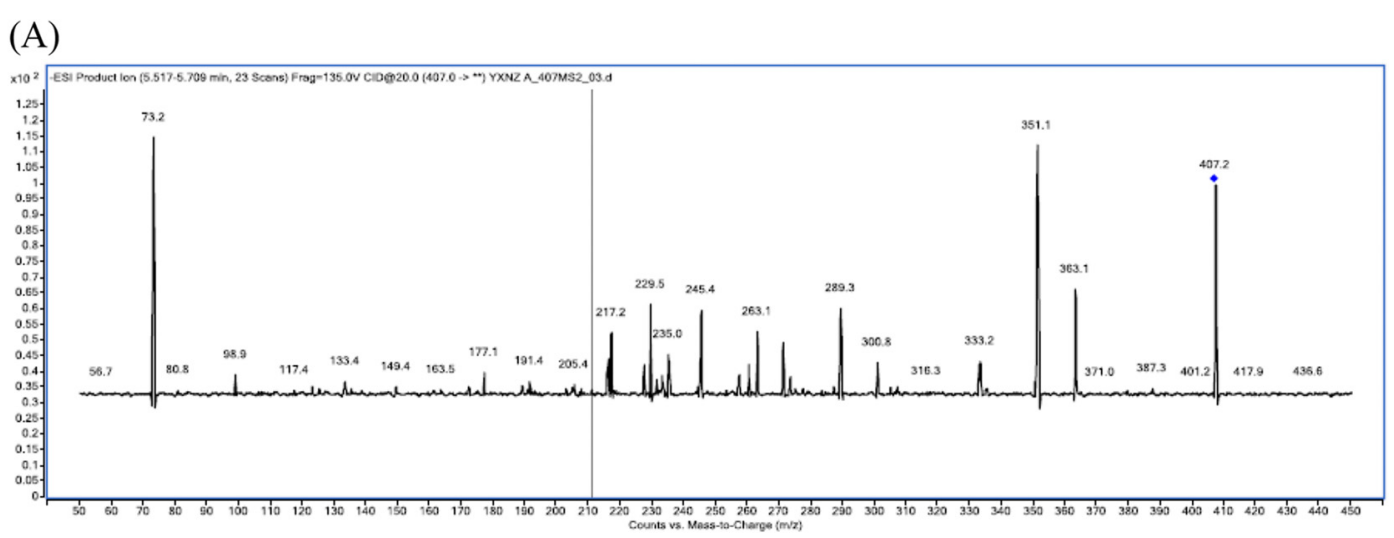

(B)

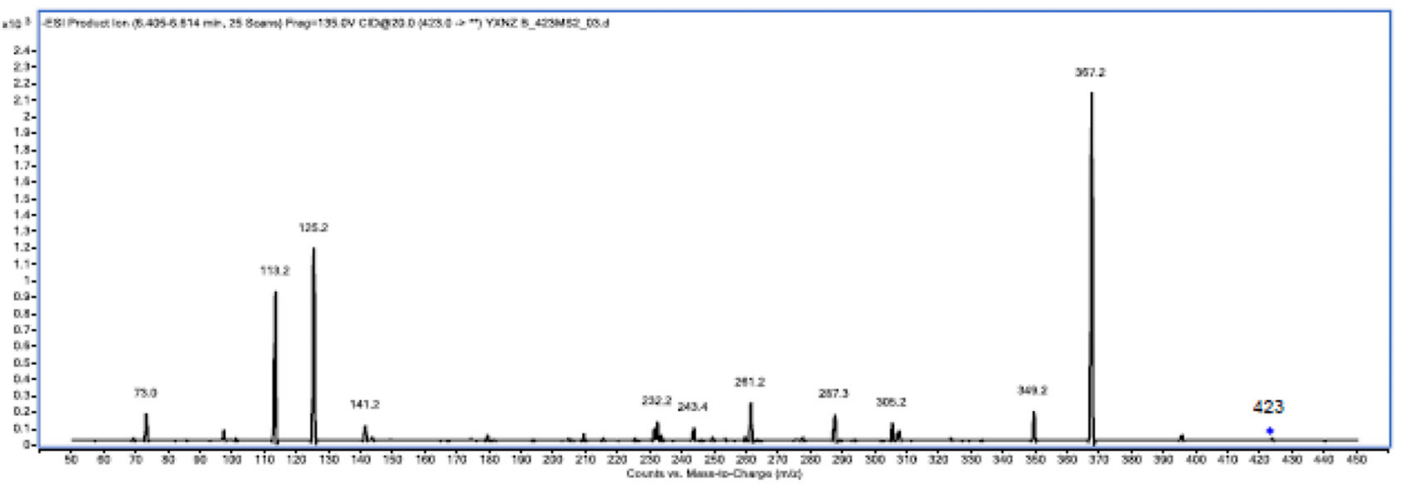

(C)

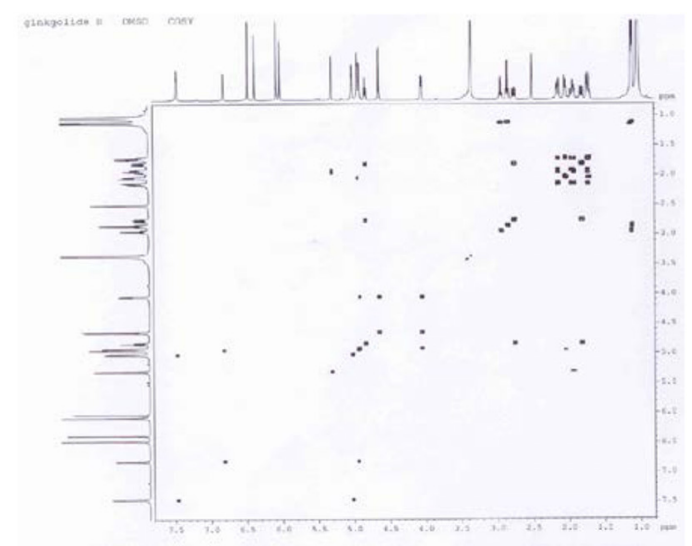

(D)

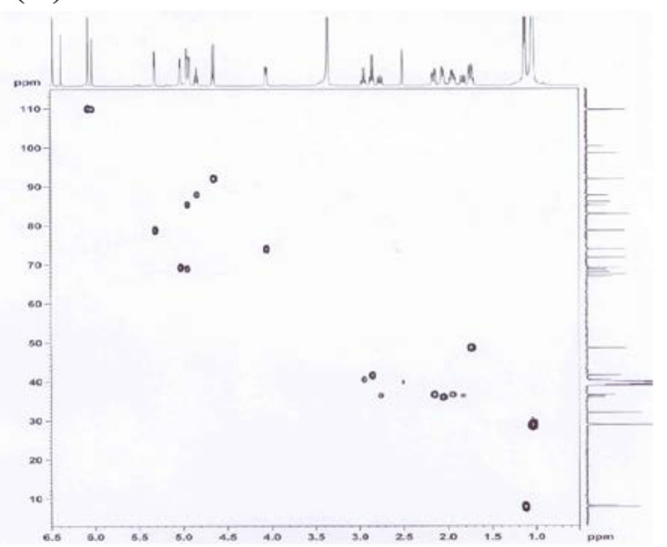

Figure 3 MS/MS and NMR chromatograms of product. (A) ESI-MS (-) MS spectrum of GA (m/z 408); (B) ESI-MS (-) MS spectrum of GB (m/z 423); (C) the $1 \mathrm{H}-1 \mathrm{H}$ COSY spectra; (D) the $1 \mathrm{H}-13 \mathrm{C}$ HSQC spectra.

2 mol reduced form of nicotinamide-adenine dinucleotide phosphate (NADPH) used as the reducing powder (NADPH). Moreover, $1 \mathrm{~mol}$ glucose is converted into $1 \mathrm{~mol}$ glucose 6-phosphate, $1 \mathrm{~mol}$ fructose 6-phosphate is converted into $1 \mathrm{~mol}$ fructose-1,6-biphosphate by two steps of phosphorylation of EMP and consume 2 adenosine-triphosphate (ATP). However, $1 \mathrm{~mol}$ fructose1,6-biphosphate can form glyceraldehydes 3-phosphate and dihydroxyacetone phosphate that can synthesize 4
ATP and 2 NADH by EMP. Therefore, 1 mol glucose can produce 2 mol ATP, 2 mol NADH and 2 mol pyruvate by EMP. In addition, $1 \mathrm{~mol}$ pyruvate is oxidized into $\mathrm{CO}_{2}$ and $\mathrm{H}_{2} \mathrm{O}$ by TCA pathway, creating $4 \mathrm{~mol}$ reduced nicotinamide adenine dinucleotide (NADH), $1 \mathrm{~mol}$ reduced flavin adenine dinucleotide (FADH) and $1 \mathrm{~mol}$ GTP, which is equal to 15 ATPs. Therefore, $1 \mathrm{~mol}$ glucose can produce 38 mol ATP by EMP and TCA cycle [33]. The increased activities of these key enzymes, 
Table 1 Assignment of the ${ }^{1} \mathrm{H}-{ }^{1} \mathrm{H}$ correlation signals found in the two-dimension COSY spectra of the transformed production

\begin{tabular}{|c|c|c|c|c|}
\hline Chemical shift (ppm) & $J(\mathrm{~Hz})$ & Number of proton & Assignment $^{\mathrm{a}}$ & ${ }^{\top} \mathrm{H}-{ }^{\prime} \mathrm{H}$ COSY \\
\hline 7.46 & $d / 5.0$ & 1 & $10-\mathrm{OH}(\mathrm{B})$ & $\mathrm{H} 10$ (B) \\
\hline 6.82 & $d / 5.2$ & 0.15 & $10-\mathrm{OH}(\mathrm{A})$ & $\mathrm{H} 10(\mathrm{~A})$ \\
\hline 6.47 & s & 1 & $3-\mathrm{OH}(\mathrm{B})$ & \\
\hline 6.38 & s & 0.15 & $3-\mathrm{OH}(\mathrm{A})$ & \\
\hline 6.07 & s & 1 & $\mathrm{H} 12$ (B) & \\
\hline 6.02 & s & 0.15 & $\mathrm{H} 12$ (A) & \\
\hline 5.30 & $d / 4.0$ & 1 & H6 (B) & $\mathrm{H} 7 \mathrm{a}, \mathrm{H} 7 \mathrm{~b}(\mathrm{~B})$ \\
\hline 5.02 & $d / 5.0$ & 1 & $\mathrm{H} 10$ (B) & $10-\mathrm{OH}(\mathrm{B})$ \\
\hline \multirow[t]{2}{*}{4.92} & $\mathrm{~m}$ & 1 & $1-\mathrm{OH}(\mathrm{B})$ & $\mathrm{H} 1$ (B) \\
\hline & & 1.14 & $\mathrm{H} 6, \mathrm{H} 10(\mathrm{~A})$ & $\mathrm{H} 7,10-\mathrm{OH}(\mathrm{A})$ \\
\hline 4.83 & $\mathrm{dd} / 7.2,8.0$ & 0.15 & $\mathrm{H} 2(\mathrm{~A})$ & $\mathrm{H} 1 \mathrm{a}, \mathrm{H} 1 \mathrm{~b}(\mathrm{~A})$ \\
\hline 4.64 & $d / 7.4$ & 1 & $\mathrm{H} 2(\mathrm{~B})$ & $\mathrm{H} 1$ (B) \\
\hline 4.04 & $\mathrm{dd} / 3 \cdot 0,7 \cdot 4$ & 1 & $\mathrm{H} 1(\mathrm{~B})$ & $\mathrm{H} 2,1-\mathrm{OH}(\mathrm{B})$ \\
\hline 2.93 & $\mathrm{q} / 7.2$ & 0.15 & $\mathrm{H} 14$ (A) & $\mathrm{H} 16$ (A) \\
\hline 2.83 & $\mathrm{q} / 7.1$ & 1 & $\mathrm{H} 14$ (B) & $\mathrm{H} 16$ (B) \\
\hline 2.75 & $\mathrm{dd} / 7.2,15.2$ & 0.15 & $\mathrm{H} 1 \mathrm{a}(\mathrm{A})$ & $\mathrm{H} 1 \mathrm{~b}, \mathrm{H} 2(\mathrm{~A})$ \\
\hline 2.15 & $\mathrm{~m}$ & 1 & $\mathrm{H} 7 \mathrm{a}(\mathrm{B})$ & $\mathrm{H} 7 \mathrm{~b}, \mathrm{H} 8$ (B) \\
\hline 2.02 & $\mathrm{~m}$ & 1.14 & $\mathrm{H} 7(\mathrm{~A})$ & $\mathrm{H} 8(\mathrm{~A})$ \\
\hline 1.96 & $\mathrm{~m}$ & 1 & $\mathrm{H} 7 \mathrm{~b}(\mathrm{~B})$ & $\mathrm{H} 6, \mathrm{H} 7 \mathrm{a}, \mathrm{H} 8$ (B) \\
\hline 1.81 & $\mathrm{dd} / 8.0,15.2$ & 0.15 & $\mathrm{H} 1 \mathrm{~b}(\mathrm{~A})$ & $\mathrm{H} 1 \mathrm{a}, \mathrm{H} 2(\mathrm{~A})$ \\
\hline \multirow[t]{2}{*}{1.72} & $\mathrm{~m}$ & 1 & $\mathrm{H} 8$ (B) & $\mathrm{H} 7 \mathrm{a}, \mathrm{H} 7 \mathrm{~b}(\mathrm{~B})$ \\
\hline & & 0.15 & $\mathrm{H} 8(\mathrm{~A})$ & $\mathrm{H} 7(\mathrm{~A})$ \\
\hline \multirow[t]{2}{*}{1.11} & $m$ & 3 & $\mathrm{H} 16$ (B) & $\mathrm{H} 14$ (B) \\
\hline & & 0.51 & $\mathrm{H} 16$ (A) & $\mathrm{H} 14$ (A) \\
\hline \multirow[t]{2}{*}{1.03} & s & 9 & $\mathrm{H} 18, \mathrm{H} 19, \mathrm{H} 20$ (B) & \\
\hline & & 1.53 & $\mathrm{H} 18, \mathrm{H} 19, \mathrm{H} 20$ (A) & \\
\hline
\end{tabular}

${ }^{a}(A): H$ assigned ginkgolide $A ;(B): H$ assigned ginkgolide $B$.

including glucose-6-phosphate isomerase, glyceraldehyde 3-phosphate dehydrogenase of EMP, 6-phosphogluconate dehydrogenase of HMP and malate dehydrogenase of TCA, suggested that the metabolism of EMP, HMP and TCA was enhanced to provide NADPH and ATP to transform multi-component ginkolide.

UDP-glucose 4-epimerase catalyzes a freely reversible reaction between UDP-galactose and UDP-glucose, and it facilitates the utilization of galactose in the wheat bran of the medium. Cobalamin-independent methionine synthase catalyzes the synthesis of methionine by transferring a methyl group from methyltetrahydrofolate to homocysteine. Amidases are enzymes that catalyze the hydrolysis of amide compounds to their corresponding carboxylic acid and ammonia [34]. Formamidase (KFase) (EC 3.5.1.9) is a key enzyme in the metabolic sequence of tryptophan [33]. Their activity increase hinted that the catabolism of protein was enhanced to provide the
ATP to transformation of ginkgolides. Succinate-CoA ligase, a mitochondrial matrix enzyme, catalyzes the reversible conversion of succinyl-COA and ADP or GDP to succinate and ATP or GTP, and at least the ADPforming enzyme is part of the Krebs cycle. The downregulation of succinate-CoA ligase suggested that more succinyl-COA was involved into TCA and TCA.

In contrast to the molecular structure of GC, GA, GB, GJ and GM, it is found that the difference between them depends on the different number and sites of the hydroxyl groups. GA contains one hydroxyl group on the R3 site, GB, GJ and GM all contain two hydroxyl groups on the R1 and R3 sites, 1 and R3, R2 and R3 sites, respectively. $\mathrm{GC}$ contains three hydroxyl groups on the R1, R2 and R3 sites. Therefore, if GA, GC, GM, and GJ are all transformed into GA, the $\mathrm{H}$ on the R1 site of GA and GJ and on the R3 site of GM are oxidized into $\mathrm{OH}$, the $\mathrm{OH}$ on the R2 site of the GC, GJ and GM are reduced into $\mathrm{H}$. 
Table 2 Assignment of the ${ }^{1} \mathrm{H}-{ }^{13} \mathrm{C}$ correlation signals found in the two-dimension HSQC and HMBC of transformed production

\begin{tabular}{|c|c|c|c|c|c|}
\hline Chemical shift (ppm) & DEPT & Numbeer of Carbon & Assignment $^{\mathrm{a}}$ & HSQC & HMBC \\
\hline 176.60 & $C$ & 0.15 & C15 (A) & & $\mathrm{H} 2, \mathrm{H} 14, \mathrm{H} 16$ (A) \\
\hline 176.39 & C & 1 & C15 (B) & & $\mathrm{H} 2, \mathrm{H} 14, \mathrm{H} 16$ (B) \\
\hline 174.34 & C & 0.15 & C11 (A) & & $\mathrm{H} 10, \mathrm{H} 12$ (A) \\
\hline 173.95 & C & 1 & C11 (B) & & $\mathrm{H} 10, \mathrm{H} 12$ (B) \\
\hline 170.80 & C & 0.15 & C13 (B) & & \\
\hline 170.28 & C & 1 & C13 (B) & & $\mathrm{H} 6$ (B) \\
\hline 109.61 & $\mathrm{CH}$ & 1 & C12 (B) & $\mathrm{H} 12$ (B) & $\mathrm{H} 8,3-\mathrm{OH}(\mathrm{B})$ \\
\hline 109.51 & $\mathrm{CH}$ & 0.15 & $\mathrm{C} 12(\mathrm{~A})$ & & $\mathrm{H} 8(\mathrm{~A})$ \\
\hline 100.26 & $C$ & 0.15 & $C 4(A)$ & & $\mathrm{H} 1 \mathrm{a}, \mathrm{H} 12,3-\mathrm{OH}$ (A) \\
\hline 98.45 & C & 1 & C4 (B) & & $\mathrm{H} 12, \mathrm{H} 14,3-\mathrm{OH}$ (B) \\
\hline 91.81 & $\mathrm{CH}$ & 1 & C2 (B) & $\mathrm{H} 2(\mathrm{~B})$ & $\mathrm{H} 1, \mathrm{H} 3$ (B) \\
\hline 87.70 & $\mathrm{CH}$ & 0.15 & $C 2(A)$ & $\mathrm{H} 2(\mathrm{~A})$ & $\mathrm{H} 1 \mathrm{~b}(\mathrm{~A})$ \\
\hline 86.08 & $\mathrm{CH}$ & 0.15 & C6 (A) & $\mathrm{H} 6(\mathrm{~A})$ & \\
\hline 85.14 & C & 0.15 & $C 3(A)$ & & $\mathrm{H} 1 \mathrm{a}, \mathrm{H} 1 \mathrm{~b}(\mathrm{~A})$ \\
\hline 82.90 & C & 1 & C3 (B) & & $\mathrm{H} 2, \mathrm{H} 14, \mathrm{H} 16,3-\mathrm{OH}$ (B) \\
\hline 78.60 & $\mathrm{CH}$ & 1 & C6 (B) & $\mathrm{H} 6$ (B) & $\mathrm{H} 7(\mathrm{~B})$ \\
\hline 73.76 & $\mathrm{CH}$ & 1 & $\mathrm{C} 1(\mathrm{~B})$ & $\mathrm{H} 1$ (B) & $\mathrm{H} 2, \mathrm{H} 16$ (B) \\
\hline 71.69 & C & 1 & C9 (B) & & \\
\hline 69.05 & $\mathrm{CH}$ & 1 & C10 (B) & $\mathrm{H} 10$ (B) & $\mathrm{H} 8,10-\mathrm{OH}(\mathrm{B})$ \\
\hline 68.74 & $\mathrm{CH}$ & 0.15 & $\mathrm{C} 10(\mathrm{~A})$ & $\mathrm{H} 10(\mathrm{~A})$ & \\
\hline 68.06 & C & 0.15 & C9 (A) & & \\
\hline 67.42 & $C$ & 1 & C5 (B) & & $\mathrm{H} 6, \mathrm{H} 7, \mathrm{H} 10,10-\mathrm{OH}$ (B) \\
\hline 66.83 & C & 0.15 & C5 (A) & & $\mathrm{H} 1 \mathrm{a}, \mathrm{H} 1 \mathrm{~b}(\mathrm{~A})$ \\
\hline \multirow[t]{2}{*}{48.56} & $\mathrm{CH}$ & 1 & $\mathrm{C} 8(\mathrm{~B})$ & $\mathrm{H} 8$ (B) & $\mathrm{H} 7, \mathrm{H} 10, \mathrm{H} 12$ (B) \\
\hline & & & & & $\mathrm{H} 18, \mathrm{H} 19, \mathrm{H} 20$ (B) \\
\hline 48.53 & $\mathrm{CH}$ & 0.15 & $\mathrm{C} 8(\mathrm{~A})$ & $\mathrm{H} 8(\mathrm{~A})$ & \\
\hline 41.52 & $\mathrm{CH}$ & 1 & C14 (B) & $\mathrm{H} 14$ (B) & $\mathrm{H} 2, \mathrm{H} 3, \mathrm{H} 16$ (B) \\
\hline 40.44 & $\mathrm{CH}$ & 0.15 & C14 (A) & $\mathrm{H} 14$ (A) & \\
\hline 36.59 & $\mathrm{CH} 2$ & 1 & C7 (B) & $\mathrm{H} 7(\mathrm{~B})$ & $\mathrm{H} 8$ (B) \\
\hline 36.31 & $\mathrm{CH} 2$ & 0.15 & $C 7(A)$ & $\mathrm{H} 7(\mathrm{~A})$ & \\
\hline 35.94 & $\mathrm{CH} 2$ & 0.15 & $\mathrm{C} 1(\mathrm{~A})$ & $\mathrm{H} 1 \mathrm{a}, \mathrm{H} 1 \mathrm{~b}(\mathrm{~A})$ & \\
\hline 31.97 & C & 1 & C17 (B) & & $\mathrm{H} 8, \mathrm{H} 18, \mathrm{H} 19, \mathrm{H} 20$ (B) \\
\hline 31.95 & C & 0.15 & $\mathrm{C} 17(\mathrm{~A})$ & & \\
\hline \multirow[t]{2}{*}{28.87} & $\mathrm{CH} 3$ & 3 & $\mathrm{C} 18, \mathrm{C} 19, \mathrm{C} 20$ (B) & H18. H19, H20 & $\mathrm{H} 8$ (B) \\
\hline & & 0.51 & $\mathrm{C} 18, \mathrm{C} 19, \mathrm{C} 20$ (A) & $\mathrm{H} 18, \mathrm{H} 19, \mathrm{H} 20$ & $\mathrm{H} 8(\mathrm{~A})$ \\
\hline 8.19 & $\mathrm{CH} 3$ & 0.15 & C16 (A) & $\mathrm{H} 16$ (A) & \\
\hline 7.85 & $\mathrm{CH} 3$ & 1 & C16 (B) & H16 (B) & H14 (B) \\
\hline
\end{tabular}

a $(A)$ : $C$ assigned ginkgolide $A$; $(B)$ : $C$ assigned ginkgolide $B$.

Namely, there may be some oxidants and reductases in the internal mycelia. Catalase is an induced enzymes and converts hydrogen peroxide into harmless water and oxygen similar to superoxide dismutase to prevent free radical damage to the body. The up-regulation of catalase exhibited an increase of the $\mathrm{H}_{2} \mathrm{O}_{2}$ content. $\mathrm{H}_{2} \mathrm{O}_{2}$ might oxidze $\mathrm{H}$ on the R3-site of GM and R1-site of GA and GJ into to $\mathrm{OH}$. Aldo/keto reductases play a key role in reducing the $\mathrm{OH}$ on the R2 site of the GC, GJ and GM into the $\mathrm{H}$ group. The $\mathrm{H}$ of these reduction reactions all comes from the NADPH, whereas the energy comes from ATP. Therefore, if the amount of glucose in the medium of 


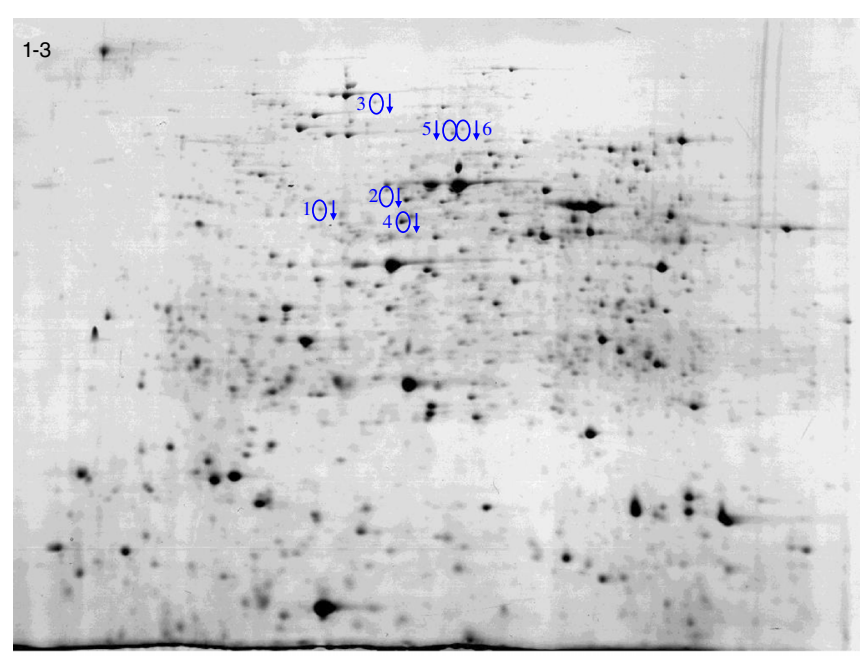

(A)

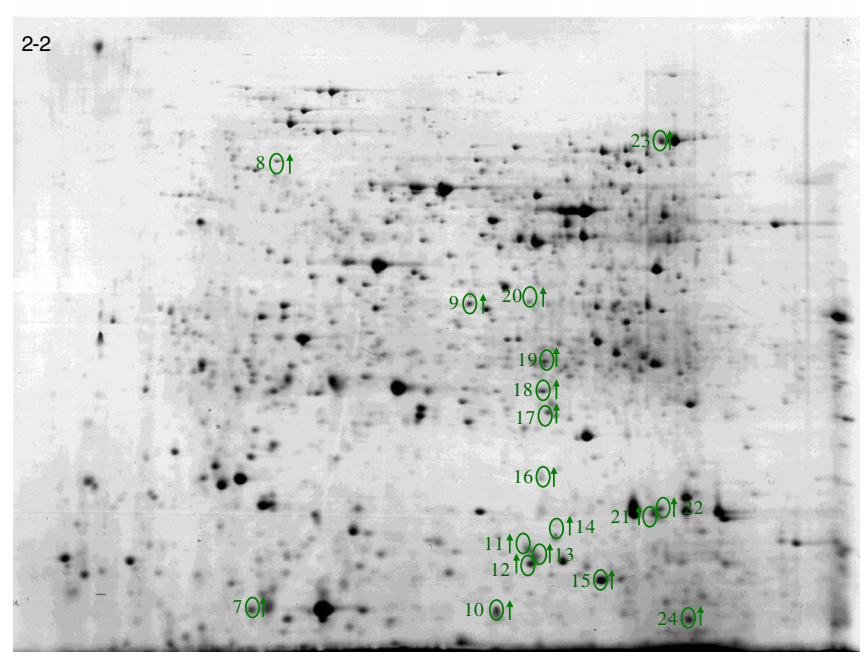

(B)

Figure 4 The 2D-gel analysis of C. comatus proteins extracted from mycelia. (A) grown in media not supplied ginkgolide; (B) grown in media supplied ginkgolide.

transformation experiment was increased, the slight amount of GA in production might be fully transformed to GB. To validate the deduction, the effect on transformation of $C$. comatus to ginkgolides was compared at different glucose concentrations, including $20 \mathrm{~g} / \mathrm{L}, 30 \mathrm{~g} / \mathrm{L}, 40 \mathrm{~g} / \mathrm{L}$, $50 \mathrm{~g} / \mathrm{L}$ and $60 \mathrm{~g} / \mathrm{L}$, and we found that all ginkgolides, including ginkgolides $\mathrm{A}$, were fully transformed into ginkgolides $\mathrm{B}$ when the glucose concentration in the medium was higher than $40 \mathrm{~g} / \mathrm{L}$.

Cyclophilins display the enzymatic activity of a peptidylprolyl isomerase (PPIase) [35,36], which catalyzes the cis to trans conversion of proline-containing peptides and facilitates protein folding. Protein folding in vivo is assisted by a set of proteins collectively known as molecular chaperones, which help successfully proteins fold to their native structures in the crowded environment of the living cells [37-39]. The up-regulation of cyclophilins and downregulation of chaperones showed that the higher structure of some enzymes and proteins was changed to convert ginkgolides into GB.

V-ATPases from in all eukaryotic cells are a type of highly conserved protein and consist of more than 10 different subunits in two functional domains. A membraneassociated domain $\left(\mathrm{V}_{0}\right)$ forms the proton channel, and a soluble catalytic domain $\left(\mathrm{V}_{1}\right)$ is involved in ATP hydrolysis [40,41]. NADP-binding protein is a type of NADP dependent protein, and it controls the rate of oxidative phosphorylation reaction by involving in dehydrogenation reaction. The down-regulation of these enzymes and proteins exhibited that the ATP applied into proton channel was decreased to provide ATP and NADH to transform ginkgolide. 


\section{Conclusions}

We developed a method to transform ginkgolide into GB by strain $C$. comatus. The product yield reached $76 \%$, and was much higher compared with conventional extraction. Analysis of LC-MS, MS/MS and NMR revealed that the transformation product included GB and GA when the medium only contained $20 \mathrm{~g} / \mathrm{L}$ glucose, and their content was $88 \%$ and $12 \%$, respectively. When the glucose concentration in medium was higher than $40 \mathrm{~g} / \mathrm{L}$, all ginkgolides were transformed into GB by C. comatus. Proteomic analysis further confirmed that the $C$. comatus transformed the ginkgolide, and the reduction power and energy for the bio-transformation were provided by NADPH and ATP, which were obtained in the process of glucose metabolism and synthesis. The method laid the found for biotransformation of active components in herbs.

\begin{abstract}
Abbreviations
EGB: Extracts of Ginkgo biloba leaves; TTLs: Terpene trilactones; GB: Ginkgolide B; GA: Ginkgolide A; GC: Ginkgolide C; GJ: Ginkgolide J; BB: Bilobalide; PDA: Potato dextrose agar; GTP: Guanosine-5'-triphosphate; ATP: Adenosine-triphosphate; NADH: Reduced nicotinamide adenine dinucleotide; FADH: Reduced flavin adenine dinucleotide; HPLC-MS: High performance liquid chromatography-Mass spectrometry; HPLC: Liquid chromatography; MS/MS: Two stage mass spectrometry; NMR: Nuclear magnetic resonance; IR spectrum: Infra-red spectrum; MS: Mass spectrum; IEF: Isoelectric focusing; COSY: Correlated spectroscopy; HSQC: Heteronuclear singular quantum correlation; ESI: Electrospray ionization; MALDITOF/ TOF: Matrixassisted laser desorption/ionization time-of-flight; DE: Two-dimensional electrophoresis; EMP: Embden-Meyerhof pathway; HMP: Hexose monophophate pathway; TCA: Tricarboxylic acid; EGTA: Ethylene glycol bis (2-aminoethyl) tetraacetic acid; PMSF: Phenylmethanesulfonyl fluoride; DTT: Dithiothreitol; TEMED: N,N,N',N'-Tetramethylethyl -enediamine; CBB: Coomassie brilliant blue; IPG buffer: Immobilized pH gradient; SDS: Sodium dodecyl sulphate.
\end{abstract}

\section{Competing interests}

The authors declare that they have no competing interests.

\section{Authors' contributions}

ZZ: design of all experiment and writing paper. JY: design of all experiment. HXD, SNC, YX: The experimental operation. All authors read and approved the final manuscript.

\section{Acknowledgements}

This work was financially supported by the Scientific and Technological Innovation Projects of Jiangsu Province General University Graduate Student (No. CXLX13_687) and the National Natural Science Foundation of China (No. 31101269). We are grateful to Mass spectra Group of Shanghai Institute Materia Medica, Chinese Academy of Sciences and the proteomic group of Boyuan Biological Science \& Technology Co., Ltd. for their excellent technical assistance.

\section{Author details}

${ }^{1}$ School of Food Science and Biotechnology, Jiangsu University, Zhenjiang, Jiangsu 212013, P. R. China. Jiangsu Tongyuantang Bio-technology Co., Ltd., Taixing, Jiangsu 225403, P. R. China.

Received: 13 August 2014 Accepted: 2 March 2015 Published online: 14 March 2015

\section{Reference}

1. Janssens D, Remacle J, Drieu K, Michiels C. Protection of mitochondrial respiration activity by bilobalide. Biochem Pharmacol. 1999;58:109-19.

2. Akisu M, Kultursay N, Coker I, Huseyinov A. Platelet-activating factor is an important mediator in hypoxic ischemic brain injury in the newborn rat
Flunarizine and Ginkgo biloba extract reduce PAF concentration in the brain. Biol Neonate. 1998;74:439-44.

3. Chung HS, Harris A. Ginkgo biloba extract increases ocular blood flowvelocity. J Ocul Pharmacol Ther. 1999;15:233-40.

4. Ranchon I, Gorrand JM. Functional protection of photoreceptors from lightinduced damage by dimethylthiourea and Ginkgo biloba extract. Invest Ophthalmol Vis Sci. 1999:40:1191-9.

5. Chen C, Wei TT, Gao Z, Zhao B, Hou J, Xu H, et al. Biochem, Different effects of the constituents of EGb761 on apoptosis in rat cerebellar granule cells induced by hydroxyl radicals. Biochem Mol Biol Int. 1999:47:397-405.

6. Lugsi A, Horvahorich P. Additional information to the in vitro antioxidant activity of Ginkgo biloba L. Phytother Res. 1999;13:160-2.

7. Sasaki K, Hatta S. Effects of bilobalide on aminobutyric acid levels and glutamic acid decarboxylase in mouse brain. Eur J Pharmacol. 1999;367:165-73.

8. Pietri S, Maurelli E, Drieu K, Culcosi M. Cardioprotective and antioxidant effects of the terpenoid constituents of Ginkgo biloba extract (EGb 761). J Mol Cell Cardiol. 1997:297:33-742.

9. Le Bars PL, Velasco FM, Ferguson JM, Dessain EC, Kieser M, Hoerr RP. Influence of the severity of cognitive impairment on the effect of the Ginkgo biloba extract EGb 761 in Alzheimer's disease. Neuropsychobiology. 2002:45:19-26.

10. Diamond BJ, Shiflett SC, Feiwel N, Mathesis RJ, Noskin O, Richards JA, et al. Ginkgo biloba extract:mechanisms and clinical indications. Arch Phys Med Rehabil. 2000;81:668-78.

11. Singh B, Kaur P, Gopichand RD, Singh PS. Biology and chemistry of Ginkgo biloba. Fitoterapia. 2008;79:401-18.

12. Maclennan KM, Darlington CL, Smith PF. The CNS effects of Ginkgo biloba extracts and Ginkgolide B. Prog Neurobiol. 2002;67:235-57.

13. Han JY, Li HJ, Chu QW, Xiao J. Progress in the research of Ginkgo biloba L. Chem Ind Eng Prog. 2000;19(2):23-7.

14. Lu DQ, Chen J. Pharmacological activities of ginkgolide. J Jiangsu University Sci Technol (Natural Sci). 2001;23(2):5-9 (in Chinese).

15. Huh HE, John S. Ontogenic aspects of ginkgolide production in Ginkgo biloba. Planta Med. 1993;59:232-9.

16. Jeon MH, Sung SH, Huh H, Kim YC. Ginkgolide B production in cultured cells derived from Ginkgo biloba L. leaves. Plant Cell Rep. 1995;14:501-4.

17. Zheng YG, Yu RM, Yao XS, Zhang H, Shao G. Study on the callus culture of Ginkgo biloba and the identification of ginkgolides. J Shenyang Pharm Uni. 1999;16:10-5.

18. Laurain D, Tremouillaux-Guiller J, Chenieux J, Van Beek TA. Production of ginkgolide and bilobalide in transformed and gametophyte derived cell cultures of Ginkgo biloba. Phytochemistry. 1997;46:127-30.

19. Loughlin WA. Biotransformations in organic synthesis. Bioresour Technol. 2000;74:49-62

20. Rather MY, Mishra S, Verma V, Chand S. Biotransformation of methyl-b-D-glucopyranoside to higher chain alkyl glucosides by cell bound $\beta$-glucosidase of Pichia etchellsii. Bioresour Technol. 2012;107:287-94.

21. Asha S, Vidyavathi M. Cunninghamella-a microbial model for drug metabolism studies-a review. Biotechnol Adv. 2009;27:16-29.

22. Wu J, Yang $X, G$ J, Zhang $Y$, Wu L, Liu J, et al. Biotransformation of sophoricoside in Fructus sophorae by the fungus Schizophyllum commune. Bioresour Technol. 2012;111:496-9.

23. Zhang ZC, Shen WL, Liu D, Li JS. Enhanced production of mycelial biomass and ganoderic acid in submerged culture of Ganoderma applanatum ACCC-52297 elicited by feeding rutin. African J Microbiol Res. 2011;5:3452-61.

24. Arakawa NS, Gobbo-Neto L, Ambrosio SR, Antonucci GA, Sampaio SV, Pupo MT, et al. Unusual biotransformation products of the sesquiterpene lactone budlein A by Aspergillus species. Phytochemistry. 2013;96:92-100.

25. Wan JY, Liu P, Wang HY, Qi LW, Wang CZ, Li P, et al. Biotransformation and metabolic profile of American ginseng saponins with human intestinal microflora by liquid chromatography quadrupole time-of-flight mass spectrometry. J Chromatography A. 2013;1286:83-92.

26. Cravedi J, Thibaut R, Tulliez J, Perdu E. Comparative in vitro study of the biotransformation of $n$-alkanes by liver and small intestine microsomes from different rat strains. Toxicol Lett. 2011;205:S188

27. Huang DM, Chang WZ, Zhang ZC, Cui FJ, Xiao X, Qian JY. Study on Anti-oxidation and Inhibitory Effect on Nonenzymatic Glycation Reaction of Fermentation Extract from Biotransformation of Ginkgo biloba L. (EGB) by Hericium erinaceus. Agri Sci Technol. 2008;9(2):10-3. in Chinese.

28. Qian JY, Zhang ZC, Huang DM, Cui FJ, Zheng HH, Chen H. Hypoglycemic Effect of Coprinus comatus Broth Biotransformating Mulberry Leaves. Edible Fungi China. 2012;31(4):46-50 (in Chinese). 
29. Huang DM, Lian B, Zhao JW, Xiao X, Zhang ZC, Cui FJ, et al. Hypoglycemic effect of the transformation products from the extract of Ginkgo biloba Leaf by Hericium erinaceus. Food Sci. 2006;27:718-2 (in Chinese).

30. Zhang ZC, Lian B, Cui FJ, Huang DM, Chang WZ. Comparisons of regulating blood glucose effects of Ginkgo biloba leaf extract with and without biotransformation by Hericium erinaceus. Mycosystema. 2008;27:420-30 (in Chinese).

31. Bradford MM. A rapid and sensitive method for the quantitation of microgram quantities of protein utilizing the principle of protein-dye binding. Anal Biochem. 1976;72:248-54.

32. Candiano G, Bruschi M, Musante L, Santucci L, Ghiggeri GM, Carnemolla B, et al. Blue silver: A very sensitive colloidal Coomassie G-250 staining for proteome analysis. Electrophoresis. 2004;2:1327-33.

33. Voet D, Voet JG. Biochemistry. 2nd ed. New York: Wiley; 1995.

34. Maestracci M, Thiery A, Arnaud A, Galzy P. A study of the mechanism of the reaction catalyzed by the amidase of Brevibacterium sp. R312. Agric Biol Chem. 1980;50:2237-41.

35. Wang P, Heitman J. The cyclophilins. Genome Biol. 2005;6:226

36. Davis TL, Walker JR, Campagna-Slater V, Finerty PJ, Paramanathan R, Bernstein G, et al. Structural and biochemical characterization of the human cyclophilin family of peptidyl-prolyl isomerases. PLoS Biol. 2010;8:e1000439.

37. Ellis RJ. Molecular chaperones: Inside and outside the Anfinsen cage. Curr Biol. 2001;11:1038-40.

38. Fenton WA, Horwich AL. Chaperonin-mediated protein folding: Fate of substrate polypeptide. Q Rev Biophys. 2003;36:229-56.

39. Young JC, Agashe VR, Siegers K, Hartl FU. Pathways of chaperonemediated protein folding in the cytosol. Nat Rev Molecular Cell Bio. 2004;5:781-91.

40. Nelson $\mathrm{N}$. The vacuolar $\mathrm{H}(+)$-ATPase-one of the most fundamental ion pumps in nature. J Exp Biol. 1992;172:19-27.

41. Taiz L. The plant vacuole. J Exp Biol. 1992;172:113-22.

\section{Submit your next manuscript to BioMed Central and take full advantage of:}

- Convenient online submission

- Thorough peer review

- No space constraints or color figure charges

- Immediate publication on acceptance

- Inclusion in PubMed, CAS, Scopus and Google Scholar

- Research which is freely available for redistribution 